\title{
Staining particulate organic matter with DTAF- a fluorescence dye for carbohydrates and protein: a new approach and application of a 2D image analysis system
}

\author{
Rhena Schumann*, Daniel Rentsch \\ Universität Rostock, FB Biologie, Freiligrathstr. 7/8, D-18051 Rostock, Germany
}

\begin{abstract}
Aggregates consist in many cases of microorganisms attached to an organic matrix. Several attempts have been made to visualise the mucoid components of the matrix by staining (e.g. alcian blue for carbohydrates and coomassie brilliant blue for proteins). Modern equipment, such as epifluorescence microscopes, flow cytometers and confocal laser scanning microscopes, requires or works best with fluorescently marked objects. Therefore, there is a great need for a fluorescent dye to visualise polysaccharides associated with aggregates. Like proteins, polysaccharides are very heterogeneous in their 3-dimensional structure. Depending on the types of interglycosidic bonds and the orders of monosaccharide building blocks, various conformations are possible (i.e. helices or molecule layers). Moreover, saccharides are very hard to modify covalently in water at natural pH levels. To date, the only available fluorescence marker is 5-(4,6-dichlorotriazinyl)aminofluorescein (DTAF), which binds covalently to polysaccharides at room temperature when the $\mathrm{pH}$ is above 9 . This paper compares the results of staining particulate organic matter (POM) with DTAF with the results of staining with the DNA-specific stain propidium iodide, which has been recently introduced to visualise detritus. Results

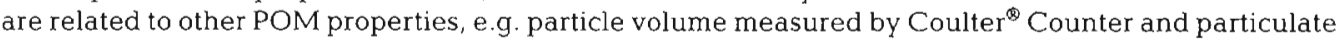
organic carbon (POC). When plankton and floccular sediment layer samples were stained with DTAF, the total particle volume was, in 13 out of 17 samples, 11 to $393 \%$ greater than that revealed by propidium iodide. The mucoid matrix of large particles ( $>50 \mu \mathrm{m}$ diameter) stained well with DTAF, whereas this material was only weakly detected with propidium iodide. In contrast, very small particles such as bacteria were seen better with propidium iodide. The total particle volume of a DTAF-stained sample calculated from 2-dimensional image analysis data correlated significantly with POC, total particulate polysaccharides, Coulter $^{\oplus}$-Counter-derived total particle volume, and light-microscope-derived summed volumes of bacteria, phytoplankton and protozooplankton. The total biovolumes contributed on average $62 \%$ of the Coulter ${ }^{(0)}$ Counter volume and $45 \%$ of propidium-iodide-stainable and $50 \%$ of DTAF-stainable volume in plankton samples from the Kirr Bucht and 58, 59 and $61 \%$ from the Rassower Strom, respectively. The remaining volume must be interpreted as the volume of amorphous detritus and, particularly in the case of the fluorescently stained particles, also as amorphous organic material.
\end{abstract}

KEY WORDS: DTAF 5-(4,6-dichlorotriazinyl)aminofluorescein - Fluorescently labelled carbohydrates · Particle size - Epifluorescence microscopy - Image analysis system - Coulter ${ }^{\oplus}$ Counter $\cdot$ Mucoid matrix of aggregates

\section{INTRODUCTION}

Particles and aggregates are important structures in the pelagial zone of aquatic ecosystems (Alldredge \& Silver 1988). There is an increasing awareness of their

•E-mail: dr.rhena.schumann@t-online.de role in organic matter cycling, as microhabitats, and as sources of nutrition (e.g. Haake \& Ittekkot 1990, Smith et al. 1992, Bauerfeind et al. 1994, Wotton 1996). Quantification of the structure and function of particulate organic matter (POM) requires, for each size class, a determination of the total organic material, a determination of protein and carbohydrate content, and a 
separation of living material from detritus. Total POM is usually estimated from particulate organic carbon (POC), e.g. by chemical oxidation of organic matter followed by IR-spectroscopic detection of the resulting carbon dioxide. To estimate POM on the basis of POC the specific carbon content of living organisms and detrital material must be considered.

Knowledge of the particle size distribution is important for interpreting the role of, e.g., marine or lake snow aggregates (e.g. Karner \& Herndl 1992, Grossart \& Simon 1993) with respect to discontinuous distributions of certain organic materials and connected microbial activities. These 'hot spots' of organic material can provide habitats for microorganisms or represent prey particles for zooplankton. However, the volume of POM and the particle size are difficult to measure. The Coulter ${ }^{\otimes}$ Counter, widely used for estimating particle volumes (Vanderploeg et al. 1987, Gaju et al. 1989, Billington 1991, Eisma et al. 1991), fails to detect detritus, and above all it cannot detect the electrolytecontaining carbohydrate matrix of aggregates in plankton samples properly (Boyd \& Johnson 1995).

Alternative methods for quantifying particle volume and size distributions are microscopic techniques combined with 2- and 3-dimensional image analysis (Psenner 1993, Verity \& Sieracki 1993). These methods are promising because they provide not only data on size classes, but allow the application of fluorescent markers for visualising diffuse gel-like structures in particles.

The mucoid organic matrix of aggregates and transparent exopolymer polysaccharides (TEP) were visualised after staining with alcian blue (Alldredge et al. 1993). Empirical histochemical observations showed this dye to be specific for negatively charged polysaccharides (Steedmann 1950, Lev \& Spicer 1964). Unfortunately there is no information available concerning its binding properties at the molecular level. Moreover, this stain does not fluoresce and therefore cannot be detected by flow cytometry, and it is only weakly detected by confocal laser scanning microscopy.

The fluorescent brightener calcofluor white and the fluorescent stain primulin are frequently used for dyeing carbohydrate containing substructures in cells and organisms (Caron 1983, Fritz \& Triemer 1985). Like alcian blue, they are non-covalent, adsorptive binding stains. Calcofluor white associates specifically with cellulose or chitin (Elorza et al. 1983, Engle et al. 1994) and is therefore particularly appropriate for cell wall staining.

There are several difficulties with the applications of propidium iodide, acridine orange and DAPI $\left(4^{\prime}, 6\right.$ diamidino-2-phenylindolej as fluorescent DNA stains for labelling detritus and biomass (Sieracki \& Viles 1992, Li \& Logan 1995, Mostajir et al. 1995, Williams et al. 1995). The specific adsorption of most DNA stains to the double helix of the DNA often causes an increase in the fluorescence intensity and can therefore lead to a halo effect and to artificially enlarged cell images. In contrast, only the nucleus in eucaryotic cells is stained brightly (Sherr et al. 1993). Furthermore, little is known about other chemical interactions of DNA stains, such as the binding of DAPI to polyphosphate coupled with a drastic increase of the Stoke's shift (e.g. Tijssen et al. 1982) or the unspecific binding to aldehyde functions (Haugland 1996).

Another specific, covalent binding protein stain is FITC (fluoresceine isothiocyanate), which has been applied to organisms and organic particles (Moreira Turcq et al. 1993, Sherr et al. 1993, Schäfer 1995). FITC does not react with carbohydrates in water under neutral to alkaline conditions and therefore cannot stain mucoid regions of aggregates. Fluorescently labelled lectins are very specific for special saccharides (Moreira Turcq et al. 1993, Waite et al. 1995, Cowen \& Holloway 1996), but because of their comparably large size they can only attach to particle or organism surfaces (cf. Van Rijssel et al. 1997). However, their high selectivity for only certain monomers results, in most cases, in weak staining which can only be detected by flow cytometry. Fluorescently marked organismspecific RNA probes (e.g. Hicks et al. 1992), which up until now have given comparably low fluorescence signals, mark only active cells. For a general visualisation of the whole microbial assemblage none of the abovementioned stains are yet applicable.

In contrast to DNA and RNA, which have a clearly defined structure, polysaccharides are structurally very diverse (Atkins 1985), and it would seem difficult to create a universal labelling reagent on the basis of non-covalent interactions for all forms of polymeric carbohydrates. Nevertheless, there is great need for a general fluorescent carbohydrate stain as a marker for total biomass and for mucoid matrices of aggregates and detritus. This would enable POM to be quantified by means of powerful optical equipment, such as flow cytometers, in addition to standard epifluorescence microscopy.

The only commercially available fluorochrome that meets these requirements is DTAF $(5-(4,6$-dichlorotriazinyl)aminofluorescein, isomeric form of fluoresceinamine dichlorotriazine). In marine ecology it has been widely and successfully applied at 50 to $60^{\circ} \mathrm{C}$ for labelling viruses, bacteria, algae and even sediment particles in proto- and metazoan grazing experiments (Sherr et al. 1987, Rublee \& Gallegos 1989, Gonzalez \& Suttle 1993, Starink et al. 1994, etc.). Surprisingly, the binding mechanism of DTAF has not been discussed. The major advantage of DTAF is, however, that it is able to react directly with polysaccharides and pep- 
tides at ambient temperatures at $\mathrm{pH}$ above 9 (De Belder \& Granath 1973, Haugland 1996), thus making it eminently suitable for undisturbed labelling of natural organic aggregates.

Unlike most nucleic acid stains, which intercalate or associate with DNA and RNA, DTAF binds covalently to primary hydroxyl functions of carbohydrates and $\mathrm{N}$-termini of proteins. The covalent binding properties and the large number of binding places (hydroxyl functions, amino groups) particularly in carbohydrates make DTAF favourable as a robust (not removable by washing procedures) intensive fluorochrome for cells, detritus and organic particles. Excitation is with blue light (maximum $493 \mathrm{~nm}$ ), giving a typical yellow-green fluorescence emission (maximum $517 \mathrm{~nm}$ ).

This paper demonstrates the usefulness of DTAF as a reliable marker for total organic material using a range of very different sample types. Particulate material was obtained from the water column, and from freshly settled surface sediment deposits at 2 stations with different eutrophication levels on the coast of the southern Baltic Sea (Fig. 1). Thus, at least 3 types of samples give the opportunity to compare the quality of the DTAF staining with other methods: (1) flocculate sediment samples with large particles (100 to $300 \mu \mathrm{m}$ diameter) and abundant mucoid substances; (2) plankton samples from a mesotrophic bodden station; (3) plankton samples from a hypereutrophic bodden. Boddens are typical tideless, shallow estuaries found along the Baltic Sea coast with salinities below 15\%.

The total particle numbers, total volume and the particle volume distribution of all samples are compared to the results obtained with the propidium iodide detritus-staining procedure (Williams et al. 1995). All data are related to particle numbers and total volume derived by the Coulter ${ }^{\circledR}$ Counter technique, POC, particulate carbohydrate concentrations and the biomass of planktonic organisms (bacteria, phytoplankton and protozoa) derived with light microscope counts using traditional counting techniques.

\section{MATERIALS AND METHODS}

Sampling. Plankton samples were taken in May, July and October 1996 at stations in the Kirr Bucht and Rassower Strom, Germany (Fig. 1). The Kirr Bucht is a small and very shallow bight (max. depth $1.5 \mathrm{~m}$, area $17 \mathrm{ha})$, with a wind-mixed water column, near the centre of a long chain of eutrophic to hypereutrophic boddens. Water exchange with the Baltic Sea is minimal. For approximately the last $10 \mathrm{yr}$ the plankton of this bodden chain has been dominated by phytoplankton consisting of colony-forming cyanobacteria and green algae with diameters of 20 to $40 \mu \mathrm{m}$ (Schumann 1993,

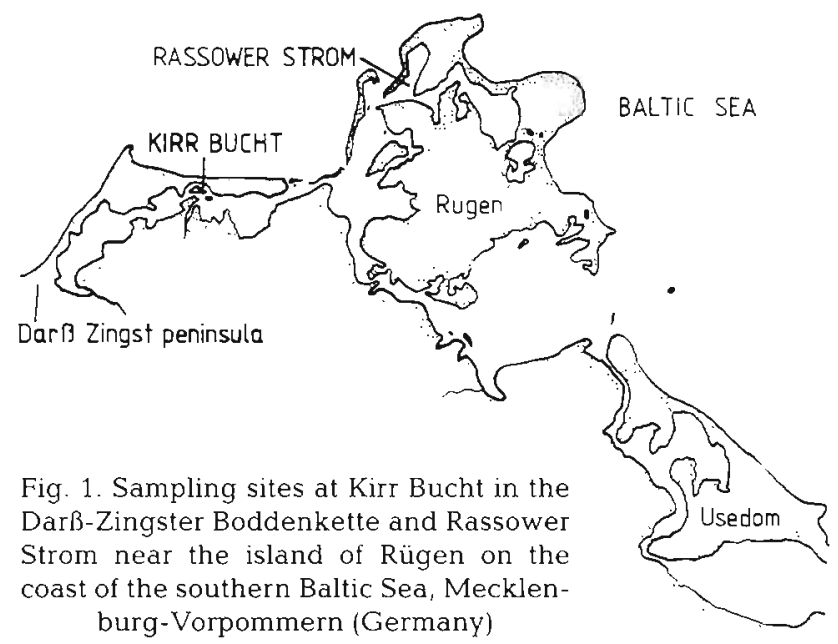

for a survey on the system see Schiewer et al. 1993). The Rassower Strom station had regular water exchange with the Baltic Sea and was $4 \mathrm{~m}$ deep; samples were taken at the surface. Plankton at this station was dominated by pigmented flagellates, and in July by chlorophytes and single-celled cyanobacteria.

Preparation of sediment samples. The floccular sediment samples were taken from 3 sediment cores $(10 \mathrm{~cm}$ diameter) by carefully siphoning off the $2 \mathrm{~mm}$ thick layer of organic material mixed with inorganic components above the sediment (Schumann \& Rentsch 1997). The very mobile coverings of the sediments so obtained were mixed together to give a volume of about $450 \mathrm{ml}$, which was then diluted with supernatant water of known composition to give a final volume of $600 \mathrm{ml}$. The data shown here refer to concentrations in the $600 \mathrm{ml}$. For the discussion of the sediment layer data with respect to sediment analysis it is possible to correct all figures to the original $2 \mathrm{~mm}$ layer.

Staining procedures. $0.5 \mathrm{ml}$ of each glutaraldehyde(1\% final concentration) fixed plankton sample and of previously diluted and fixed sediment layer samples (1:10 in particle free $8.5 \% \mathrm{NaCl}$ ) were mixed with $100 \mu \mathrm{M}$ DTAF (Sigma) in carbonate buffer adjusted to pH 9.5 for staining at room temperature (DeBelder \& Granath 1973, Haugland 1996). DTAF concentration could be reduced to $100 \mu \mathrm{M}$, which was below the amount used for bacterial staining by Sherr et al. (1987), without loss of brightness of dyed particles. A time series indicated that best results occurred after $12 \mathrm{~h}$. Counterstaining with DAPI (after Porter \& Feig 1980) showed that after at least 12 h all DNA-containing material dyed by DAPI was already stained sufficiently by DTAF. The incubation of samples at temperatures of about $50^{\circ} \mathrm{C}$ (e.g. Sherr et al. 1987 for bacteria, Starink et al. 1994 for sediment particles, Posch \& Arndt 1996 for detritus particles) is not necessary if the staining procedure lasts for more than $12 \mathrm{~h}$. 
The samples were then filtered onto irgalan blackened $0.2 \mu \mathrm{m}$ Isopore ${ }^{\otimes}$ polycarbonate membranes (Sigma) with a pressure of -200 mbar. They were washed with $8.5 \% \mathrm{NaCl}$ until no more DTAF was present in the filtrate. Filters were mounted onto slides and covered with immersion oil (Olympus) and a cover slip.

The nucleic acid stains DAPI and acridin orange showed, besides some non-specific reactions, a relatively high and variable background fluorescence, which disturbed the image analysis procedure. In contrast, samples stained with propidium iodide had an even, dark background. Non-specific dyeing of copepod chitin or other structures not containing nucleic acids seemed to be less frequent with propidium iodide. Therefore propidium iodide was chosen as a nucleic acid stain for cells and organism-derived detritus to be compared with the carbohydrate and protein stain DTAF. The staining procedures for DAPI (Porter \& Feig 1980), which here was only applied to bacteria, and for propidium iodide (Williams et al. 1995) were slightly altered in that the samples were first filtered onto the polycarbonate membranes and then stained using the stock solutions described in the literature. The larger sediment layer particles in particular were more reproducibly stained and appeared brighter with this procedure. After staining for $5 \mathrm{~min}$, the dye solutions were removed by filtering, and the filters were washed with $1 \mathrm{ml} 8.5 \% \mathrm{NaCl}$. DAPI stains the DNA of live and dead cells, whereas propidium iodide dyes only the DNA of dead material (Williams et al. 1995 Haugland 1996) as it cannot permeate intact membranes. In the case of the fixed samples analysed in this work, propidium iodide should have marked all DNAcontaining particles fluorescently.

Microscopic image analysis of particle size distribution. The samples were examined using an Olympus $\mathrm{BH} 2$-RFCA epifluorescence microscope with a magnification of $200(20 \times$ objective without oil), as the aim was to find larger particles. The smallest size detectable with this set-up was $1 \mu \mathrm{m}$, so that most of the bacteria remained invisible. The filter sets were UV (UG 1) for DAPI, green (BP 545) for propidium iodide and blue (BP 490) for DTAF.

At least 30 images per sample were taken with a Proxicam black and white video camera (Proxitronic, Bensheim, Germany) and transferred to the black and white image analysis software CUE 2 (Galai, Israel). This software shows images in 256 grey levels on a Sony Trinitron $512 \times 512$ resolution monitor. Threshold was set manually for every image to exclude background noise and compensate for differences in staining brightness, if necessary. In Rassower Strom samples, which had low particle concentrations, 289 to 2161 particles were analysed. In Kirr Bucht samples,
3655 to 10575 objects were investigated, and 464 to 4078 particles were investigated in sediment layer samples.

The following parameters were recorded for all objects: 36 'ferret' diameters including largest diameter (maximum ferret) and smallest diameter (minimum ferret), size (average diameter), area, perimeter and shape factor. Ferret diameters are distinct diameters determined at $0^{\circ}$ orientation (the vertical diameter) and every $10^{\circ}$ in rotation in the case of 36 ferrets. To calculate a volume out of such 2 -dimensional data, the largest and smallest diameters were used to estimate a spheroid shaped object, as indicated by Knowles \& Wells (1996) to be appropriate. Total particle volume of a sample consisted of the sum of all individual volumes. Size classes were built logarithmically from 0.01 to $100000 \mu^{3}$. The size class distributions show the percentage of particles in a given class and the total volume of all particles belonging to this class.

Additional characteristics of POM. Particle number and individual volume of the same samples were investigated with a Coulter ${ }^{2}$ Counter Multisizer II applying a $70 \mu \mathrm{m}$ orifice capillary. Larger orifice diameter could not be used because of the large numbers of very small particles present even in 1:1000 times diluted samples. Two or more of these small particles often passed the opening of the capillary at the same time, triggering the coincidence warning. This terminated the measurement and did not allow the successful analysis of some sediment layer samples without a greater dilution error (loss of larger and much rarer particles).

POC was measured with a TOC 5000A total organic carbon analyser (Shimadzu) equipped with a suspended particle kit (Shimadzu) after catalytic high temperature oxidation (Sugimura \& Suzuki 1988), and subtracting the dissolved organic carbon content (Whatman GF/F filtered samples). Particulate carbohydrate amounts were estimated according to Burney \& Sieburth (1977) after chemical hydrolysis. The values were also corrected by subtracting the dissolved carbohydrate concentrations.

Bacteria were counted after staining with DAPI (Porter $\&$ Feig 1980). Biovolume was calculated from a volume factor of $0.15 \mu \mathrm{m}^{3}$ per cell as was used in Klinkenberg \& Schumann (1995) for samples from these waters. Phytoplankton samples were fixed with Lugol solution, counted and measured for volume estimation under an inverted microscope. Protozoa were quantified alive (Dale \& Burkill 1982) in a rafter chamber containing a 0.5 to $1 \mathrm{ml}$ sample for ciliates and larger flagellates, and in a blood counting chamber for smaller flagellates $(<10 \mu \mathrm{m})$. Ciliate and flagellate abundances of individuals larger than $20 \mu \mathrm{m}$ were rechecked in the Lugol-fixed samples during phytoplankton analysis. 
Data analysis. The Mann-Whitney rank sum test was used for comparison of the medians of 2 particle volume distributions. Due to the large amount of very small particles a second test of significant differences between volume medians was carried out with all particles larger than $1 \mathrm{\mu m}^{3}$.

\section{RESULTS}

\section{Staining results}

In addition to staining organisms, which fluoresced bright yellow, DTAF also stained mucoid structures between cells with a weak yellow-green colour (Fig. 2a). The fluorescence of such gelatinous regions of aggregates depended obviously on the concentration of carbohydrates in them. On the surfaces of mineral particles only cells were dyed (Fig. 2b). The inorganic material itself did not show fluorescence caused by attachment of the dye. Any remaining non-covalently bound DTAF was removed by washing the samples with carbonate buffer, thus improving the resolution between objects and background. Even scattering of light by mineral particles did not reduce the image quality.

The thorough staining of the main carbohydrate and protein components of organisms obtained with DTAF produced data suitable for calculating the whole cell volume (Fig. 2d). In most cases, DNA stains such as DAPI produced clear and bright visualisations only of the nuclear region of eucaryotes, or the core DNA-containing region in procaryotes (Fig. 2C). Using chlorophyll a fluorescence is more appropriate for cell volume determination in cyanobacteria, as the chlorophyll is more evenly distributed in the cells (Fig. 2e).

Fig. 2f, g shows contrasting images of the same aggregates from a sediment layer sample double stained with DTAF and propidium iodide. Whereas the yellow DTAF fluorescence indicated a complete staining of the whole matrix (Fig. 2f), the red fluorescence of the DNA stain showed only bacteria-shaped objects associated with a weakly fluorescing background (Fig. 2g).

\section{Estimating the total particle volume and abundance}

After analysing the particles with a 2-dimensional monochrome image analysis system, the DTAF staining of plankton produced a lower particle count (on average $32 \%$ less, with a range of 8 to $82 \%$ ) compared to the propidium-iodide-staining procedure in nearly all samples. Most of the 'lost' particles were very small bacteria-shaped objects. The greatest differences occurred in the samples from Rassower Strom, which had few relatively large particles. However, the total particle volume with DTAF staining was considerably larger in 7 of 10 samples (Table 1)

The total particle numbers were similar when the 2 staining procedures were applied to the sediment layer samples, which contained larger aggregates, Except for 1 sample, the detected particle volume was higher by $122 \%$ (range 39 to $393 \%$ ) after DTAF staining (Table 2).

Table 1 Particle numbers $\left(10^{6} \mathrm{ml}^{-1}\right)$ and total particulate volume $\left(\mathrm{mm}^{3} \mathrm{I}^{-1}\right)$ of plankton samples from the Kirr Bucht and Rassower Strom after staining with DTAF or propidium iodide (PI). Values in bold type indicate that total particle volume with DTAF was larger

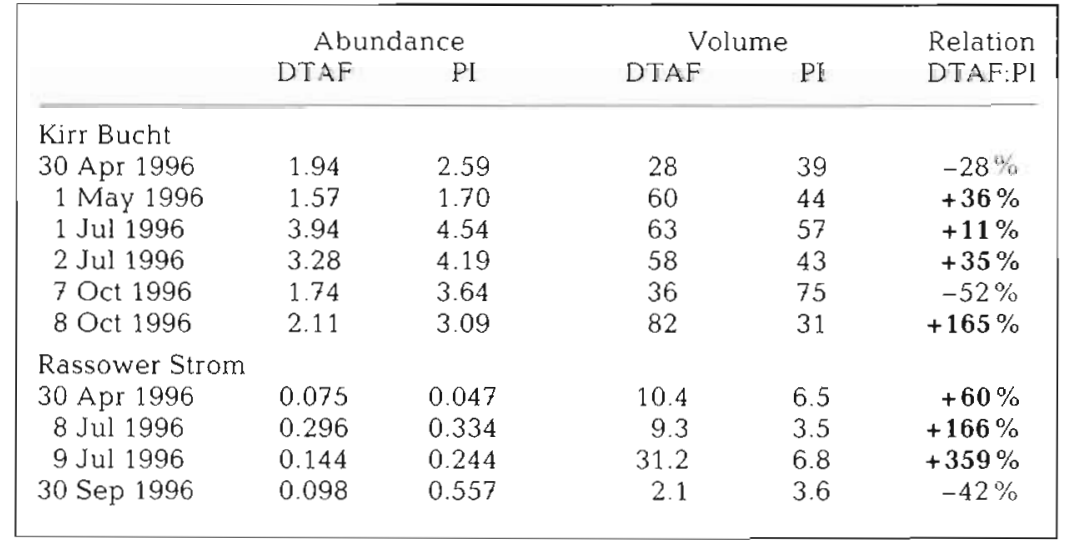

Table 2. Particle numbers $\left(10^{5} \mathrm{ml}^{-1}\right)$ and total particulate volume $\left(\mathrm{mm}^{3} \mathrm{l}^{-1}\right)$ of samples from the fluffy sediment layer after staining with DTAF or propidium iodide (Pl). Values in bold type indicate that total particle volume with DTAF was larger

\begin{tabular}{|lrrrrr|}
\hline & \multicolumn{2}{c}{ Abundance } & \multicolumn{2}{c|}{ Volume } & Relation \\
& DTAF & PI & DTAF & PI & DTAF:PI \\
\hline Kirr Bucht & & & & & \\
1 May 1996 & 6.0 & 3.7 & 4820 & 850 & $\mathbf{+ 3 9 3 \%}$ \\
1 Jul 1996 & 13.1 & 13.1 & 4320 & 2060 & $\mathbf{+ 1 1 0 \%}$ \\
2 Jul 1996 & 7.4 & 6.3 & 2790 & 1800 & $+\mathbf{5 5} \%$ \\
7 Oct 1996 & 10.3 & 11.3 & 4380 & 2570 & $+\mathbf{7 0} \%$ \\
Rassower Strom & & & & & \\
30 Apr 1996 & 2.2 & 3.1 & 1710 & 1060 & $+\mathbf{6 2} \%$ \\
8 Jul 1996 & 2.8 & 7.2 & 1760 & 2810 & $-37 \%$ \\
30 Sep 1996 & 2.6 & 1.4 & 1650 & 1190 & $+39 \%$ \\
\hline
\end{tabular}



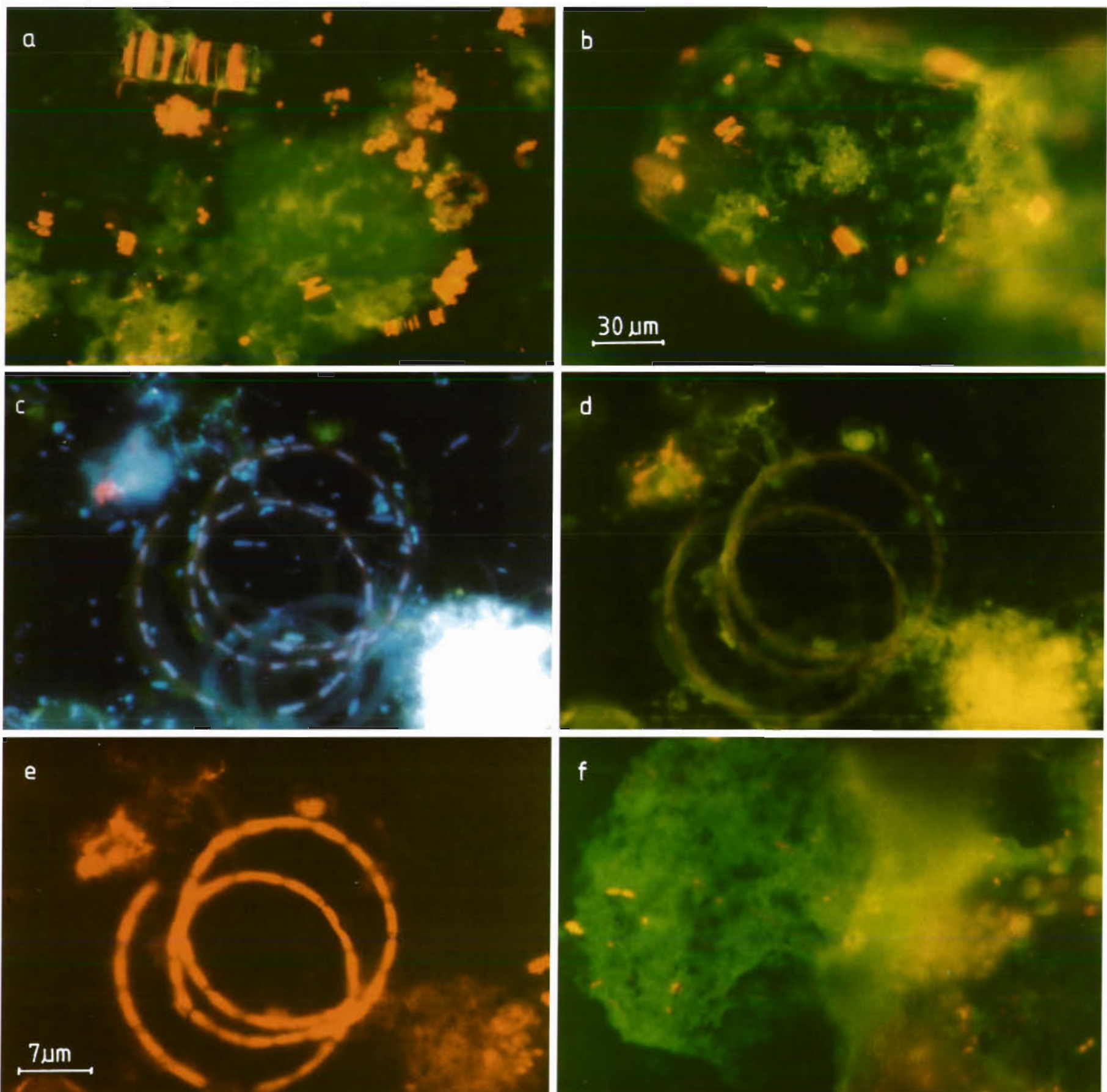

f

Fig. 2. (a) Organic mucus-rich aggregate and (b) mineral particle with attached organisms of a flocculate sediment layer sample from the Kirr Bucht ( 7 April 1997) stained for $12 \mathrm{~h}$ with DTAF. Magnification 200x. Excitation: blue, BP $490 \mathrm{~nm}$. Red fluorescence from chlorophyll a. (c-e) Trichom of Lyngbya contorta from the Kirr Bucht plankton sample ( 7 April 1997) stained with DTAF for $12 \mathrm{~h}$ and counterstained with DAPI for $5 \mathrm{~min}$. Magnification $1000 \mathrm{x}$ oil immersion. Excitation: (c) UV, BP $410 \mathrm{~nm}$ white-blue colour of DAPI stained DNA; (d) blue, BP $490 \mathrm{~nm}$ yellow-green colour of DTAF stained carbohydrates and proteins; (e) green, BP $545 \mathrm{~nm}$ red colour of chlorophyll a. (f, g) Organic aggregate with bacteria and cyanobacteria from a glutardialdehyde fixed flocculate sediment layer sample (cf. $a, b)$ stained $12 \mathrm{~h}$ with DTAF and counterstained with propidium iodide for $5 \mathrm{~min}$. Magnification $1000 \times$, oil immersion. Excitation: (f) blue, BP $490 \mathrm{~nm}$ yellow-green DTAF and orange-red chlorophyll $a_{i}(\mathrm{~g})$ green, BP $545 \mathrm{~nm}$ red fluorescence of propidium iodide and chlorophyll $a$

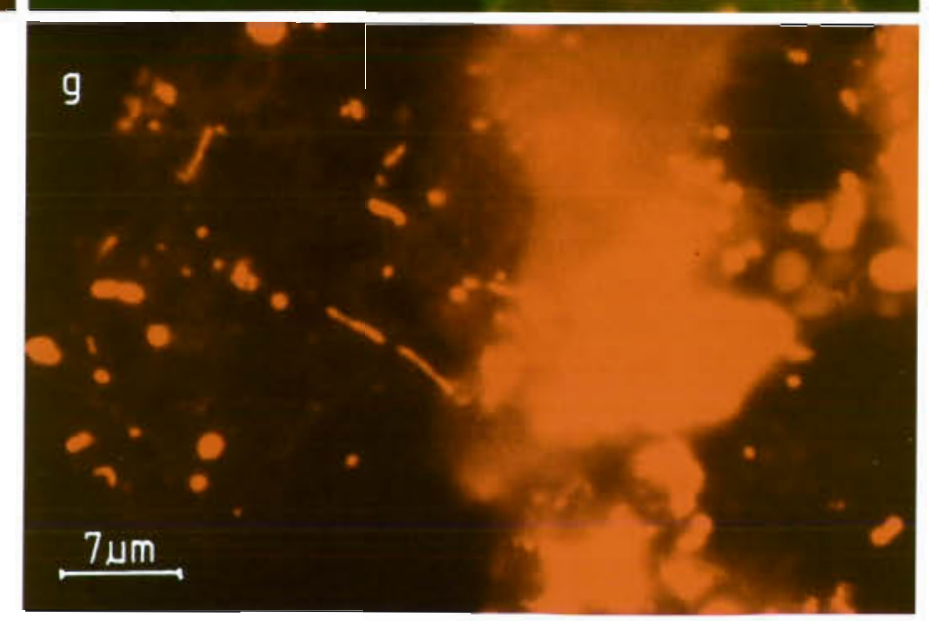




\section{Particle volume distribution}

The higher total particle volumes detected in most DTAF-stained samples should also be reflected by different particle volume distributions. Most $(66$ to $95 \%$ ) objects had volumes between 0.1 and $10 \mu \mathrm{m}^{3}$ independent of the staining procedure and sample type (Table 3). Particles larger than $10000 \mu^{3}$ were found only twice in plankton samples stained with propidium iodide, but could be detected in all but 1 sample stained with DTAF. With respect to volume, the most important size class in the case of propidium iodide was that between 10 and $10000 \mu \mathrm{m}^{3}$, but with DTAF most of the volume was contributed by particles between 100 and $100000 \mathrm{~mm}^{3}$. For the propidium-iodide-stained sedi-

Table 3. Range of particle portions (\%) in volume-based size classes $\left(\mu \mathrm{m}^{3}\right)$ and of the contribution of the total class volume to the whole particle volume $(\%)$ of samples stained with propidium iodide and with DTAF

\begin{tabular}{|c|c|c|c|c|}
\hline Class & $\begin{array}{l}\text { Plar } \\
\text { Kirr Bucht } \\
n=6\end{array}$ & $\begin{array}{l}\text { kton } \\
\text { Rassower Strom } \\
\qquad n=4\end{array}$ & $\begin{array}{c}\text { Sedir } \\
\text { Kirr Bucht } \\
n=4\end{array}$ & $\begin{array}{c}\text { ment layer } \\
\text { Rassower Strom } \\
n=3\end{array}$ \\
\hline \multicolumn{5}{|c|}{ Propidium iodide } \\
\hline $0.01-0.1$ & $5.6-7.6$ & $3.8-9.3$ & $4.2-8.6$ & $10.4-18.4$ \\
\hline $0.1-1$ & $39.4-49.6$ & $38.0-66.1$ & $34.7-38.5$ & $28.2-33.5$ \\
\hline $1-10$ & $35.8-40.0$ & $25.2-38.6$ & $30.8-39.2$ & $22.6-23.4$ \\
\hline $10-100$ & $6.2-14.1$ & $4.0-17.1$ & $12.3-15.7$ & $12.3-14.9$ \\
\hline $100-1000$ & $1.0-2.3$ & $0.8-3.4$ & $4.0-7.0$ & $6.1-12.6$ \\
\hline $1000-10000$ & $0.1-0.5$ & $0.1-0.3$ & $1.4-3.3$ & $4.5-5.9$ \\
\hline $10000-100000$ & $0-0.02$ & 0 & $0.6-0.6$ & $0.5-1.4$ \\
\hline$>100000$ & 0 & 0 & $0-0.05$ & $0-0.2$ \\
\hline \multicolumn{5}{|l|}{ Particle volume } \\
\hline $0.01-0.1$ & $0.02-0.05$ & $0.02-0.05$ & 0 & 0 \\
\hline $0.1-1$ & $0.8-2.2$ & $0.6-4.2$ & 0.1 & $0.02-0.04$ \\
\hline $1-10$ & $4.1-13.4$ & $4.5-13.4$ & $0.4-0.7$ & $0.1-0.3$ \\
\hline $10-100$ & $12.0-36.4$ & $17.9-36.4$ & $1.4-3.0$ & $0.5-1.6$ \\
\hline $100-1000$ & $17.4-49.2$ & $24.3-45.1$ & $4.6-10.1$ & $3.0-14.6$ \\
\hline $1000-10000$ & $10.5-65.6$ & $10.5-52.7$ & $23.0-52.3$ & $18.6-55.1$ \\
\hline $10000-100000$ & $0-27.8$ & 0 & $34.9-68.2$ & $26.6-53.8$ \\
\hline$>100000$ & 0 & 0 & $0-26.4$ & $0-51.2$ \\
\hline \multicolumn{5}{|l|}{ DTAF } \\
\hline \multicolumn{5}{|l|}{ Particle numbers } \\
\hline $0.01-0.1$ & $3.3-8.1$ & $4.5-8.5$ & $4.6-10.1$ & $14.1-24.4$ \\
\hline $0.1-1$ & $30.0-45.9$ & $32.8-37.3$ & $30.3-36.8$ & $28.3-31.4$ \\
\hline $1-10$ & $36.6-46.8$ & $32.5-41.9$ & $34.0-41.0$ & $20.7-26.5$ \\
\hline $10-100$ & $7.4-16.4$ & $11.4-19.7$ & $12.2-16.0$ & $13.1-16.1$ \\
\hline $100-1000$ & $1.2-3.1$ & $1.9-6.9$ & $3.1-4.5$ & $3.2-7.9$ \\
\hline $1000-10000$ & $0.1-0.4$ & $0-1.0$ & $1.2-3.3$ & $4.6-5.6$ \\
\hline $10000-100000$ & $0.02-0.08$ & $0-0.7$ & $0.9-1.4$ & $1.3-1.5$ \\
\hline$>100000$ & 0 & 0 & $0.03-0.22$ & $0-0.2$ \\
\hline \multicolumn{5}{|l|}{ Particle volume } \\
\hline $0.01-0.1$ & $0.01-0.03$ & $0-0.02$ & 0 & 0 \\
\hline $0.1-1$ & $0.4-1.3$ & $0.1-0.7$ & $0.02-0.05$ & 0.02 \\
\hline $1-10$ & $3.0-9.5$ & $0.7-5.7$ & $0.1-0.4$ & 0.1 \\
\hline $10-100$ & $7.4-21.9$ & $1.6-37.0$ & $0.7-1.4$ & $0.7-0.8$ \\
\hline $100-1000$ & $10.0-42.8$ & $5.7-56.5$ & $1.5-3.8$ & $1.6-4.5$ \\
\hline $1000-10000$ & $14.5-42.0$ & $0-30.2$ & $12.6-22.2$ & $26.1-27.2$ \\
\hline $10000-100000$ & $19.0-50.2$ & $0-82.1$ & $42.3-63.7$ & $37.3-70.6$ \\
\hline$>100000$ & 0 & 0 & $12.8-39.9$ & $0-31.2$ \\
\hline
\end{tabular}

ment layer samples the volume of particles $>10000 \mu^{3}$ was $55 \%(28$ to $78 \%$ ) of the total volume. Stained with DTAF, however, these size classes contributed on average $75 \%$ (68 to $82 \%$ ) to the total particulate volume.

When comparing plankton and sediment layer samples stained with propidium iodide or DTAF, e.g. from the Kirr Bucht (July 2, 1996, Fig. 3), it was clear that the majority of particles were in the smaller size classes $\left(<10 \mu \mathrm{m}^{3}\right)$, but that their contribution to particle volume was negligible. The larger, very rare particles (>10000 $\mathrm{\mu m}^{3}$, less than $1 \%$ of all analysed objects per sample) contributed $73 \%$ of the DTAF-stained and $67 \%$ of the propidium-iodide-stained total volume in the sediment layer samples shown in Fig. 3. It was difficult to accurately reproduce results in this important size range because of the infrequent occurrence of the very large particles. Additionally, very slight differences in the minimal and maximal diameter influence the calculated volume strongly.

\section{Average particle volume}

The discrepancies in total volume and the occurrence of larger particles after DTAF staining should lead to statistically significant differences in average object parameters. A comparison of the particle volume distributions of 17 samples stained with DTAF or propidium iodide showed that in 6 cases the median volumes were larger with DTAF staining, with 9 cases being not significantly different, and 2 being significantly lower (Table 4 ). The extremely high number of very small particles (Table 2) had a negligible contribution to total volume but strongly influenced the calculation of the median volume. As the volume distributions were strongly weighted towards small particles, tests for significant differences were restricted to non-parametric rank sum tests for non-normally distributed groups, e.g. Mann-Whitney test. Thus, the differences in median volume did not show so clearly the advantage of DTAF in staining organic aggregates in the larger size classes. To remove the influence of small objects, a second test run was employed with the removal of all objects $<1 \mu^{3}$. The vol- 

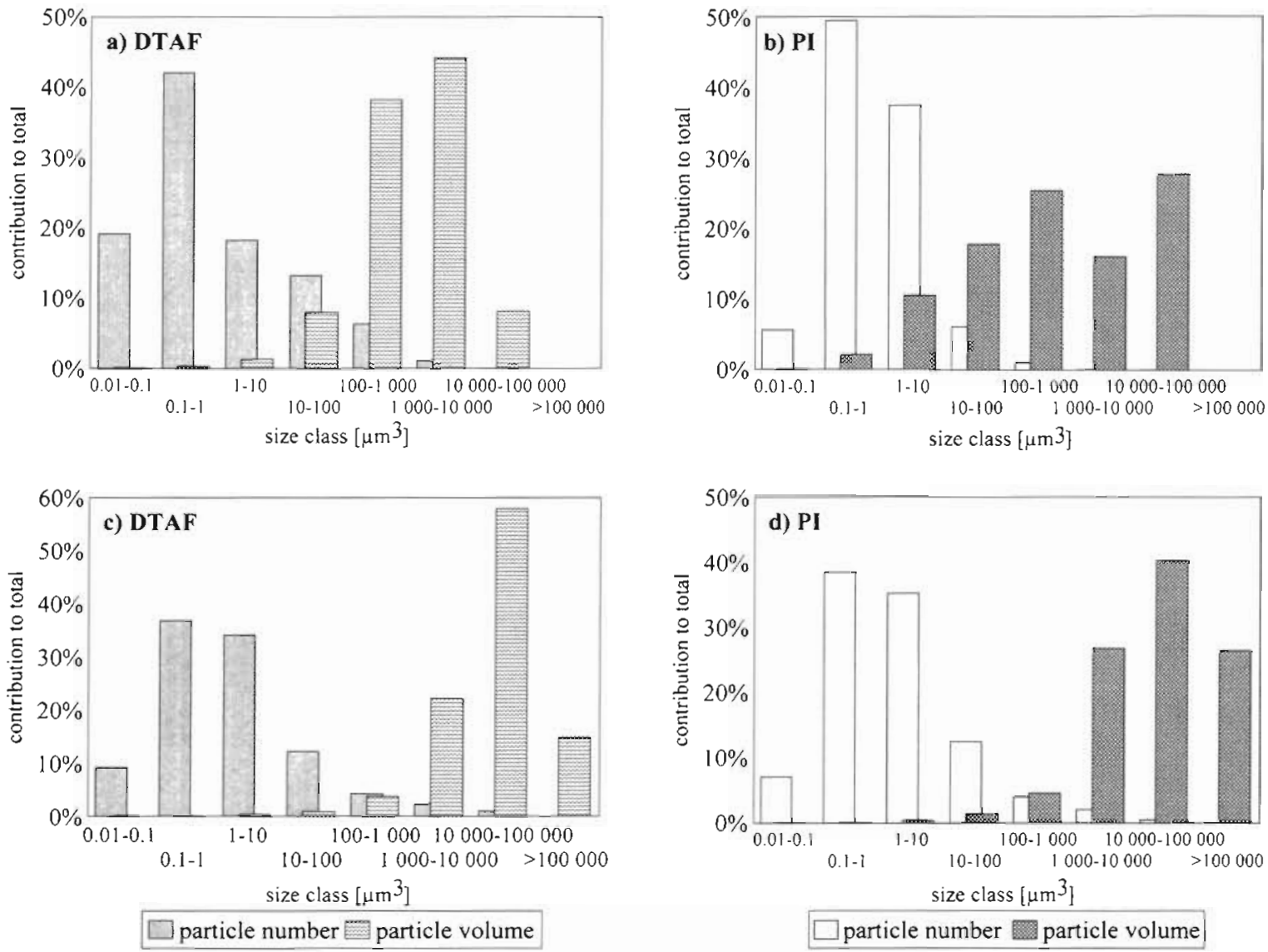

Fig. 3. Distribution of particle numbers and particle volumes in samples from the Kirr Bucht (July 2, 1996) logarithmically built size classes between 0.01 and $100000 \mu \mathrm{m}^{3}$ per particle from $(\mathrm{a}, \mathrm{b})$ the plankton and $(\mathrm{c}, \mathrm{d})$ the flocculate sediment layer stained with $(a, c)$ DTAF and $(b, d)$ propidium iodide

Table 4. Median means of particle volume for propidium iodide staining and DTAF staining (italicised values indicate a significantly higher volume median confirmed by Mann-Whitney rank sum test, $p<0.05$ ) of all particles and of only those particles larger than $1 \mu \mathrm{m}^{3}$ (for number of particles see 'Materials and methods')

\begin{tabular}{|c|c|c|c|c|c|}
\hline & & \multicolumn{2}{|c|}{ All particles } & \multicolumn{2}{|c|}{ Particles larger than $1 \mu \mathrm{m}^{3}$} \\
\hline & & DTAF & Propidium iodide & DTAF & Propidium iodide \\
\hline \multicolumn{6}{|l|}{ Kirr Bucht } \\
\hline \multirow[t]{6}{*}{ Plankton } & 30 Apr 1996 & 1.25 & 1.00 & 3.27 & 3.14 \\
\hline & 1 May 1996 & 0.79 & 0.79 & 3.40 & 3.12 \\
\hline & 1 Jul 1996 & 0.79 & 0.79 & 2.57 & 2.93 \\
\hline & 2 Jul 1996 & 0.79 & 0.73 & 2.60 & 2.40 \\
\hline & 7 Oct 1996 & 1.66 & 1.00 & 4.47 & 3.20 \\
\hline & 8 Oct 1996 & 1.66 & 0.79 & 4.59 & 2.84 \\
\hline \multirow[t]{4}{*}{ Sediment layer } & 1 May 1996 & 1.53 & 1.38 & 6.82 & 7.18 \\
\hline & $1 \mathrm{Jul} 1996$ & 1.26 & 1.49 & 5.59 & 5.35 \\
\hline & 2 Jul 1996 & 1.01 & 1.06 & 5.40 & 5.18 \\
\hline & 7 Oct 1996 & 1.66 & 1.34 & 5.63 & 5.18 \\
\hline \multicolumn{6}{|l|}{ Rassower Strom } \\
\hline \multirow[t]{4}{*}{ Plankton } & 30 Apr 1996 & 1.66 & 0.73 & 7.29 & 4.86 \\
\hline & 8 Jul 1996 & 1.56 & 1.17 & 4.44 & 5.13 \\
\hline & 9 Jul 1996 & 1.51 & 1.30 & 4.16 & 6.00 \\
\hline & 30 Sep 1996 & 1.66 & 0.51 & 6.23 & 1.66 \\
\hline \multirow[t]{3}{*}{ Sediment layer } & 30 Apr 1996 & 1.78 & 1.65 & 12.8 & 19.7 \\
\hline & 8 Jul 1996 & 0.63 & 1.33 & 10.9 & 7.23 \\
\hline & 30 Sep 1996 & 0.68 & 0.76 & 12.7 & 14.3 \\
\hline
\end{tabular}


ume distributions remained inclined and non-normal, and the Mann-Whitney test showed 7 samples with significantly larger DTAF-stained volumes and only 1 with a significantly lower volume (Table 4).

\section{Organic particle volume in relation to other POM characteristics}

In order to test the reliability of the POM volume derived from image analysis data, comparisons were made with a range of other parameters describing the properties of particulate matter. The total particle volume derived with a Coulter ${ }^{(i)}$ Counter correlated significantly with that obtained with image analysis of both DTAF-and propidium-iodide-stained samples (Table 5). Highly significant correlations were also detected between POC and estimates of total volume from image analysis. Other significant correlations were found between particulate carbohydrates and Coulter volume. The ratio between total volumes measured after DTAF and propidium iodide staining was 1.3 for Kirr Bucht pelagic samples containing many plankton cells, but was higher at 2.4 for Rassower Strom pelagic samples and 2.1 for sediment layer samples, which obviously had more mucus-containing aggregates. The correlation between microscopically estimated summed biovolumes of phytoplankton, bacteria and protozoa and the volumes estimated with image analysis was significant, but not as good as with POC, due to the variable amount of detritus in the samples.

The contribution of phytoplankton, bacterial, and protozoan biovolumes to the total particle volume in plankton samples averaged for the Kirr Bucht 62\% (24 to $117 \%$ ) of the Coulter ${ }^{\circledR}$ Counter volume, $45 \%$ (26 to $68 \%$ ) of propidium-iodide-stainable and $50 \%$ (19 to $67 \%$ ) of DTAF-stainable volume. In Rassower Strom samples the biovolume contributed $58 \%$ (20 to $118 \%$ ), 59\% (23 to $83 \%$ ) and $61 \%(14$ to $142 \%)$, respectively. When the biomass exceeded that of the Coulter ${ }^{(0)}$ Counter, or the DTAF-stained volume, this was due to either the Coulter ${ }^{(3)}$ Counter not detecting dead cells (Boyd \& Johnson 1995) or bacteria smaller than 1.4 $\mu \mathrm{m}$ in sphere equivalent diameter, and to the insufficient DTAF staining of small bacteria for the relatively low magnification of $200 \times$. The variability, however, between individual samples was high. An analysis of the DTAF-calculated total particle volume is shown in Fig. 4 for a Kirr Bucht pelagic sample: $6 \%$ of the total volume was bacterial, $3 \%$ was from protozoa and $30 \%$ was from phytoplankton, and the remaining $61 \%$ was assumed to be detritus or the mucoid areas of organic particles; $43 \%$ of the biomass and detritus volume was detectable with the Coulter ${ }^{\circledast}$ Counter and $58 \%$ with propidium iodide staining (relative to DTAF-derived values).
Table 5. Correlation matrix of data describing POM properties. CC: volume of Coulter ${ }^{\otimes}$ Counter $\left(\mu 11^{-1}\right)$; PI: propidium iodide stained $\left(\mu \mathrm{ll}^{-1}\right)$, DTAF: DTAF stained $\left(\mu \mathrm{l} \mathrm{l}^{-1}\right)$, POC: particulate organic carbon $\left(\mu \mathrm{mol} \mathrm{Cl^{-1 }}\right.$; $\mathrm{PCHO}$ : particulate carbohydrates $\left(\mu \mathrm{mol} \mathrm{C}^{-1}\right)$; $\mathrm{BV}$ : biovolume of phytoplankton, bacteria and protozoa $\left(\mu \mathrm{l}^{-1}\right)$. Only CC, PI and DTAF include data on sediment layer samples, the others include only plankton samples. ( $\alpha<0.05, \cdots \alpha<0.01$ and $\cdots \alpha<0.001)$

\begin{tabular}{|ccccccc|}
\hline & $\mathrm{CC}$ & $\mathrm{PI}$ & DTAF & POC & PCHO & $\mathrm{BV}$ \\
\hline $\mathrm{CC}$ & 1 & & & & & \\
$\mathrm{PI}$ & $0.696 \cdots$ & 1 & & & & \\
$\mathrm{n}=$ & 13 & & & & & \\
DTAF & $0.784 \cdots$ & $0.777 \cdots$ & 1 & & & \\
$\mathrm{n}=$ & 13 & 17 & & & & \\
POC & $0.984^{\cdots} \cdots$ & $0.987 \cdots$ & $0.985 \cdots$ & 1 & & \\
$\mathrm{n}=$ & 9 & 9 & 9 & & & \\
PCHO & $0.988 \cdots$ & 0.581 & 0.435 & $0.989 \cdots$ & 1 & \\
$\mathrm{n}=$ & 11 & 11 & 11 & 9 & & \\
$\mathrm{BV}$ & 0.657 & $0.838 \cdots$ & 0.784 & 0.474 & 0.522 & 1 \\
$\mathrm{n}=$ & 8 & 8 & 8 & 8 & 8 & \\
& 8 & & & & & \\
\end{tabular}

\section{DISCUSSION}

The recently recognised importance of aggregatecoupled microbial activity (e.g. Karner \& Herndl 1992, Smith et al. 1992, Grossart \& Simon 1993) demands the analysis of size classes of organic particles and of the substrate quality occurring in them.

Several methods are currently in use for determining the total particle volume of aquatic samples, some based on conductivity differences of the sample, e.g. the Coulter ${ }^{\otimes}$ Counter (e.g. Gaju et al. 1989, Billington 1991), others using optical properties of the sample, e.g. underwater photography (Eisma et al. 1990, 1991.

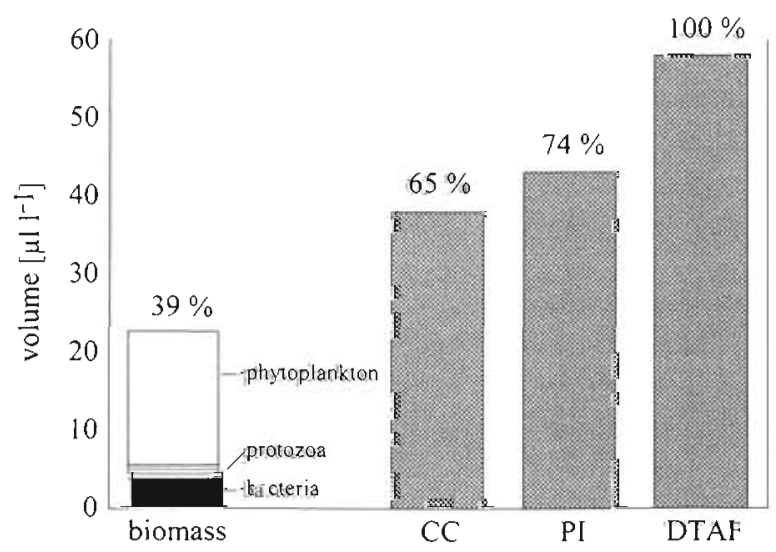

Fig. 4. Total biovolume of bacteria, protozoa and phytoplankton $\left(\mathrm{Hl} \mathrm{I}^{-1}\right)$ compared to Coulter ${ }^{(-)}$Counter (CC) volume and propidium-iodide-stained and DTAF-stained particle volume $\left(\mu \mathrm{l}^{-1}\right.$. DTAF volume assumed as $\left.100 \%\right)$ from the Kirr Bucht plankton sample (2 July 1996) 
Kilps et al. 1994, Knowles \& Wells 1996). Computerassisted 2-dimensional microscopic image analysis is an established technique for estimating the size and shape of microorganisms viewed with transmitted light (Van Wambeke 1988, Sieracki \& Viles 1990, Weeks \& Richards 1993). Fluorescence microscopy has the advantage of revealing otherwise invisible or indistinguishable structures, either using naturally occurring fluorochromes (e.g. chlorophyll; Estep \& MacIntyre 1989, Walsby \& Avery 1995) or after adding artificial fluorochromes to label a structure of interest (e.g. Krambeck et al. 1990, Yamaguchi et al. 1995). Video images of fluorescent structures are of high contrast: bright colour against a more or less black background. Therefore, the determination of threshold levels in which the choice is made between object pixels and background pixels is comparably easy.

The original use of DTAF was to fluorescently label certain polysaccharides, in particular dextrans, in order to follow their fate in animal or human tissue (e.g. Letourneur et al. 1993) or to label proteins, a role in which the relative resistance of DTAF to hydrolysis was confirmed (Siegler et al. 1989). Remarkably, binding with DTAF did not alter the reactivity and biological function of the protein molecule (Keith et al. 1981).

Sherr et al. (1987) introduced the DTAF-labelling technique for preparing fluorescently marked bacteria as prey organisms for protozoa. Unfortunately, they did not discuss the staining mechanism. They found that best staining results could be obtained by incubation of bacteria with DTAF for $2 \mathrm{~h}$ at $60^{\circ} \mathrm{C}$. This heating step of course killed the prey particles, which may have lead to altered ingestion rates. To avoid killing the prey organisms, several attempts were subsequently made with fluorescent redox indicators, such as cyanoditolyl tetrazolium chloride (Epstein \& Rossel 1995) or hydroethidine (Putt 1991). But, these fluorochromes are not appropriate for staining amorphous organic matter in aggregates.

We found that if the incubation of organic particles with DTAF was prolonged for more than $12 \mathrm{~h}$ at $\mathrm{pH}$ well above 9, then sufficient staining was observed at room temperature. In this way it was possible to stain living organisms as well as dead cells and amorphous material. However, stained algae often showed only weak yellow fluorescence, as chlorophyll fluorescence induced by the blue excitation light was much brighter than from DTAF (cf. Fig. 2a, c, e). This could explain the unsatisfactory staining results with this dye which have been reported with algae (Putt 1991).

Bacteria stained with DTAF were not as bright as those prepared with DNA stains such as DAPI or propidium iodide (cf. Fig. 2c, d), because in contrast to DTAF the binding of these fluorochromes to DNA enhances the fluorescence intensity of the dye immensely
(Haugland 1996). When using DNA stains, either with DTAF or alone, it should be considered that the halo effect of DNA-specific stains (Krambeck et al. 1990) resulting from the increase in fluorescence intensity may distort the image so that the true size or shape of bacteria is obscured. The inaccuracy caused by this effect is even worse in the case of eucaryotes, where often only the nucleus is stained sufficiently for automatic image analysis.

Williams et al. (1995) tried a variety of fluorochromes with target structures such as polysaccharides, membranes and nucleic acids for differential staining of detritus and living material. They recommended a set of nucleic acid stains: the membrane permeable DAPI for all DNA-containing particles, and the non-permeable propidium iodide for only dead material. This approach, based on differences in membrane permeability, is very useful as there are many different nucleic acid stains with different permeabilities (Haugland 1996).

We have shown here that for the staining of particulate organic material, especially the mucoid areas in aggregates, the application of DTAF is very useful. The covalent coupling to saccharides and protein not only provides many binding places in biomass, mucoid matrices around cells or in aggregates, but ensures the staining of organic material without generating too much noise in the images via adsorptive attachment to other objects, e.g. inorganic particles. In addition, it would be possible to combine DTAF staining with other fluorochromes for the selective labelling of live or dead individual microorganisms, as mentioned above.

In plankton samples from the eutrophic Kirr Bucht and the Rassower Strom an average of 50 and $61 \%$, respectively, of the DTAF-stained particle volume was contributed by summed bacterial, protozoan and phytoplankton biomass. The remaining 50 and $39 \%$, respectively, was probably amorphous particulate detritus, as it was not recognised by traditional microscopic counting techniques. So, about half of the volume of particulate organic matter in the pelagial was not connected to plankton organisms. This again underlines the importance of aggregates in pelagic systems, even when the particles are as small $(<200 \mu \mathrm{m})$, as in the investigated coastal waters of the southern Baltic Sea, and of further microscopic investigations of the nature of particulate organic matter in addition to chemical examinations.

The DTAF staining of carbohydrates and protein exceeded the total propidium-iodide-stained and DNAcontaining particle volume by 11 to $359 \%$ in 7 out of 10 plankton samples and by 39 to $393 \%$ in 6 out of 7 flocculate sediment layer samples. These higher total volumes resulted in most cases from the additional occurrence of larger particles through staining of the 
mucoid matrix between cells, whereas the propidium iodide stained only individual cells. Therefore DTAF staining of aggregates is the appropriate method to characterise size classes and numbers of organic aggregates as the basis for studies of aggregateassociated microorganisms.

For the application of automated image analysis routines, a problem occurs when regions with uneven brightness are found within one object; in this case one has to return to semi-automatic routines. DTAF staining of biomass, however, produced evenly stained objects without large halo effects and with clearly marked outlines of the whole cells or organic particles. Therefore, DTAF not only is appropriate to mark carbohydrates and protein in organisms and mucoid regions of aggregates, but complements perfectly the use of automatic imaging systems combined with epifluorescence microscopy.

Acknowledgements. This work was financially supported by the Ministry of Education, Science, Technology and Research (BEO 71/03F0161W). We thank U. Schiewer and R. Forster for their comments and suggestions on the manuscript and $\mathrm{R}$. Forster for correcting the language. The data on planktonic protozoa of the Rassower Strom station were provided by $\mathrm{R}$. Verhoeven (Institut für Ökologie, Kloster, Hiddensee, Germany).

\section{LITERATURE CITED}

Alldredge AL, Passow U, Logan BE (1993) The abundance and significance of a class of large, transparent organic particles in the ocean. Deep Sea Res I 40:1131-1140

Alldredge AL, Silver MW (1988) Characteristics, dynamics and significance of marine snow. Prog Oceanogr 20:41-82

Atkins EDT (ed) (1985) Polysaccharides. Topics in structure and morphology. Weinheim, Deerfield Beach, FL

Bauerfeind E, Bodungen BV, Arndt K, Koeve W (1994) Particle flux, and composition of sedimenting matter, in the Greenland Sea. J Mar Syst 5:411-423

Billington N (1991) A comparison of three methods of measuring phytoplankton biomass on a daily and seasonal basis. Hydrobiologia 226:1-15

Boyd CM, Johnson GW (1995) Precision of size determination of resistive electronic particle counters. J Plankton Res 17: $41-58$

Burney CM, Sieburth JMcN (1977) Dissolved carbohydrates in seawater II, a spectrophotometric procedure for total carbohydrate analysis. Mar Chem 5:15-28

Caron DA (1983) Technique for enumeration of heterotrophic and phototrophic nanoplankton, using epifluorescence microscopy, and comparison with other procedures. Appl Environ Microbiol 46:491-498

Cowen JP, Holloway CF (1996) Structural and chemical analysis of marine aggregates: in situ macrophotography and laser confocal and electron microscopy. Mar Biol 126: 163-174

Dale T, Burkill PH (1982) Live counting - a quick and simple technique for enumerating pelagic ciliates. Ann Oceanogr 58:267-276

De Belder AN, Granath K (1973) Preparation and properties of fluorescein labelled dextrans. Carbohydr Res 30: $375-378$

Eisma D, Bernard P, Cadee GC, Ittekkot V, Laane R, Martin JM, Mook WG, Van Put A, Schuhmacher T, Kalf J (1991) Suspended-matter particle size in some west-European estuaries; Part 1. particle-size distribution. Neth J Sea Res 28:193-214

Eisma D, Schuhmacher $T$, Boekel $H$, Heerwaarden JV, Franken $H$, Laan M, Vaars A, Eijgenraam F, Kalf J (1990) A camera and image-analysis system for in situ observation of flocs in natural waters. Neth J Sea Res $27: 43-56$

Elorza MV, Rico H, Sentandreu R (1983) Calcofluor white alters the assembly of chitin fibrils in Saccharomyces cerevisiae and Candida albicans cells. J Gen Microbiol 129: $1577-1582$

Engle AR, Purdie N, Hyatt JA (1994) Induced circular dichroism study of the aqueous solution complexation of cello-oligosaccharides and related polysaccharides with aromatic dyes. Carbohydr Res 265:181-195

Epstein SS, Rossel J (1995) Methodology of in situ grazing experiments: evaluation of a new vital dye for preparation of fluorescently labelled bacteria. Mar Ecol Prog Ser 128: $143-150$

Estep KW, MacIntyre F (1989) Counting, sizing, and identification of algae using image analysis. Sarsia 74:261-268

Fritz L. Triemer R (1985) A rapid simple technique utilizing calcofluor white M2R for the visualization of dinoflagellate thecal plates. J Phycol 21:662-664

Gaju N, Guerrero R, Pedros Alio C (1989) Measurement of cell volume of phototrophic bacteria in pure cultures and natural samples: phase contrast, epifluorescence and particle sizing. FEMS Microbiol Ecol 62:295-302

Gonzalez JM, Suttle CA (1993) Grazing by marine nanoflagellates on viruses and virus-sized particles: ingestion and digestion. Mar Ecol Prog Ser 94:1-10

Grossart HP, Simon M (1993) Limnetic macroscopic organic aggregates (lake snow): occurrence, characteristics, and microbial dynamics in Lake Constance. Limnol Oceanogr 38:532-546

Haake B, Ittekkot V (1990) The wind-driven 'biological pump' and carbon removal in the ocean. Naturwissenschaften 77 : $75-79$

Haugland RP (1996) Handbook of fluorescent probes and research chemicals, 6th edn. Molecular Probes Inc, Eugene, OR

Hicks RE, Amann RI, Stahl DA (1992) Dual staining of natural bacterioplankton with 4',6-diamidino-2-phenylindole and fluorescent oligonucleotide probes targeting kingdomlevel 16S rRNA sequences. Appl Environ Microbiol 58: 2158-2163

Karner M, Herndl GJ (1992) Extracellular enzymatic activity and secondary production in free-living and marinesnow-associated bacteria. Mar Biol 113:341-347

Keith CH, Feramisco JR, Shelanski M (1981) Direct visualisation of fluorescein-labelled microtubules in vitro and in microinjected fibroblasts. J Cell Biol 88:234-240

Kilps JR, Logan BE, Alldredge AL (1994) Fractal dimensions of marine snow determined from image analysis of in situ photographs. Deep Sea Res A Oceanogr Res Pap 41: $1159-1169$

Klinkenberg G, Schumann R (1995) Abundance changes of autotrophic and heterotrophic picoplankton in the Zingster Strom, a shallow, tideless estuary south of the DarßZingst Peninsula (Southern Baltic Sea). Arch Hydrobiol 134:359-377

Knowles SC, Wells JT (1996) Suspended aggregate analysis us- 
ing ISAAC, Elbe River, 9-10 June 1993. J Sea Res 36:69-75 Krambeck C, Krambeck HJ, Schröder D, Newell SY (1990) Sizing bacterioplankton: juxtaposition of bias due to shrinkage, halos, subjectivity in image interpretation and asymmetric distributions. Binary Comput Microbiol 2:5-14

Letourneur D, Logeart D, Avramoglou T, Jozefonvicz J (1993) Antiproliferative capacity of synthetic dextrans on smooth muscle cell growth: the model of derivatized dextrans as heparin-like polymers. J Biomater Sci Polym Ed 4:431-444

Lev R, Spicer SS (1964) Specific staining of sulphate groups with alcian blue at low pH. J Histochem Cytochem 12:309

Li X, Logan BE (1995) Size distributions and fractal properties of particles during a simulated phytoplankton bloom in a mesocosm. Deep Sea Res II 42:125-138

Moreira Turcq P, Martin JM, Fleury A (1993) Chemical and biological characterization of particles by flow cytometry in the Krka estuary, Croatia. Mar Chem 43:115-126

Mostajir B, Dolan JR, Rassoulzadegan F (1995) A simple method for the quantification of a class of labile marine pico- and nano-sized detritus: DAPI Yellow Particles (DYP). Aquat Microb Ecol 9:259-266

Porter KG, Feig YS (1980) The use of DAPI for counting and identifying aquatic microflora. Limnol Oceanogr 25: 943-948

Posch T, Arndt $\mathrm{H}$ (1996) Uptake of submicrometre- and micrometre-sized detrital particles by bacterivorous and omnivorous ciliates. Aquat Microb Ecol 10:45-53

Psenner R (1993) Determination of size and morphology of aquatic bacteria by automated image analysis. In: Kemp PF, Sherr BF, Sherr EB, Cole JJ (eds) Handbook of methods in aquatic microbial ecology. Lewis Publishers, Boca Raton, p 339-345

Putt M (1991) Development and evaluation of tracer particles for use in microzooplankton herbivory studies. Mar Ecol Prog Ser 77:27-37

Rublee PA, Gallegos CL (1989) Use of fluorescently labelled algae (FLA) to estimate microzooplankton grazing. Mar Ecol Prog Ser 51:221-227

Schäfer $H$, Siedler $M$, Beisker W, Müller $K$, Steinberg CEW (1995) Flow cytometry applied to ataxonomic assessment of phytoplankton. Vom Wasser 84:379-389

Schiewer U, Schlungbaum G, Arndt EA (eds) (1993) 20 Jahre Boddenforschung-Monographie Rostocker Meeresbiologische Beiträge 2, Univ Rostock

Schumann R (1993) Zur Rolle des Pico- und Nanophytoplanktons im mikrobiellen Nahrungsgefüge der Darß-Zingster Boddenkette. PhD thesis, Univ Rostock

Schumann R, Rentsch D (1997) Charakterisierung von Aggregatgrößenklassen in der Sedimentauflage der Kirr Bucht. (Darß-Zingster Boddenkette). Bodden 5:195-206

Sherr BF, Sherr EB, Falloni RD (1987) Use of monodispersed fluorescently labeled bacteria to estimate in situ protozoan bacterivory. Appl Environ Microbiol 53:958-968

Sherr EB, Caron DA, Sherr BF (1993) Staining of heterotrophic protists for visulization via epifluorescence microscopy. In: Kemp PF, Sherr BF, Sherr EB, Cole JJ (eds) Handbook of methods in aquatic microbial ecology. Lewis Publishers, Boca Raton, p 213-227

Siegler R, Sternson LA, Stobaugh JF (1989) Suitability of DTAF as a fluorescent labelling reagent for direct analysis of primary and secondary amines - spectral and chemical reactivity considerations. J Pharm Biomed Anal 7:45-55
Sieracki ME, Viles CL (1990) Color image-analyzed fluorescence microscopy: a new tool for marine microbial ecology. Oceanography 3:30-36

Sieracki ME, Viles CL (1992) Distributions and fluorochromestaining properties of submicrometer particles and bacteria in the North Atlantic. Deep Sea Res 39:1919-1929

Smith DC, Simon M, Alldredge AL, Azam F (1992) Intense hydrolytic enzyme activity on marine aggregates and implications for rapid particle dissolution. Nature 359: $139-142$

Starink M, Krylova IN, Baer Gilissen MJ, Bak RPM, Cappenberg TE (1994) Rates of benthic protozoan grazing on free and attached sediment bacteria measured with fluorescently stained sediment. Appl Environ Microbiol 60 $2259-2264$

Steedmann HF (1950) Alcian blue 8GS: a new stain for mucin Q J Microsc Sci 91:477-479

Sugimura Y, Suzuki Y (1988) A high temperature catalytic oxidation method for the determination of non-volatile dissolved organic carbon in seawater by direct injection of a liquid sample. Mar Chem 24:105-131

Tijssen JP, Beekes HW, Van Steveninck J (1982) Localization of polyphosphates in Saccharomyces fragilis, as revealed by 4',6-diamidino-2-phenylindole fluorescence. Biochim Biophys Acta 721:394-398

Vanderploeg HA, Eadie BJ, Liebig JR, Tarapchak SJ, Glover RM (1987) Contribution of calcite to the particle-size spectrum of Lake Michigan seston and its interactions with the plankton. Can J Fish Aquat Sci 44:1898-1914

Van Rijssel M, Hamm CE, Gieskes WWC (1997) Phaeocystis globosa (Prymnesiophyceae) colonies: hollow structures built with small amounts of polysaccharides. J Phycol 32 $185-192$

Van Wambeke F (1988) Enumeration and sizing of planktonic bacteria by image-analysed epifluorescence microscopy Ann Inst Pasteur Microbiol 139:261-272

Verity PG, Sieracki ME (1993) Use of color image analysis and epifluorescence microscopy to measure plankton biomass. In: Kemp PF, Sherr BF, Sherr EB, Cole JJ (eds) Handbook of methods in aquatic microbial ecology. Lewis Publishers, Boca Raton, p 327-338

Waite AM, Olson RJ, Dam HG, Passow U (1995) Sugarcontaining compounds on the cell surfaces of marine diatoms measured using concanavalin $\mathrm{A}$ and flow cytometry. J Phycol 31:925-933

Walsby AE, Avery A (1995) Measurement of filamentous cyanobacteria by image analysis. J Microbiol Methods 26: $11-20$

Weeks PJD, Richards L (1993) Morphometric analysis of Chlorella fusca var. vacuolata: a comparison of image analysis and Coulter counting. Binary Comput Microbiol $5: 29-36$

Williams S, Verity PG, Beatty T (1995) A new staining technique for dual identification of plankton and detritus in seawater. J Plankton Res 17:2037-2047

Wotton RS (1996) Colloids, bubbles, and aggregates-a perspective on their role in suspension feeding. J North Am Benthol Soc 15:127-135

Yamaguchi M, Itakura S, Imai I, Ishida Y (1995) A rapid and precise technique for enumeration of resting cysts of Alexandrium spp. (Dinophyceae) in natural sediments. Phycologia 34:207-214

Submitted: September 9, 1997; Accepted: December 5, 1997 Proofs received from author(s): February 9, 1998 